\title{
Lo que cuenta el (nuevo) Símbolo Internacional de Accesibilidad
}

What the (new) International Symbol of Access tells

\section{Palabras clave}

Símbolo accesibilidad, comunicación, discapacidad.

\section{Keywords}

Accessibility symbol, communication, disability.

\section{Luis Bascones}

$<$ Imbascones@consultoria. ilunion.com>

Ilunion Tecnología y Accesibilidad. España

\section{1. 'Accesible': del hecho al dicho}

El nuevo Símbolo Internacional de Accesibilidad (SIA) propuesto por Naciones Unidas en diciembre de 2015 pretende dar un giro en la comprensión de la accesibilidad respecto al icono clásico, la silla de ruedas. La interacción humana se basa en el uso de imágenes y símbolos para comprenderse, constituir identidades y relacionarse entre grupos. Los símbolos movilizan además emociones y se relacionan con acciones, modos de trato.

Más allá de la intención y el acierto del diseño para transmitir significados, el sentido de los logos de accesibilidad se produce en contextos de uso concretos, ¿qué implica cuando aparece en el frontal de un autobús, en una señal de estacionamiento reservado o en el menú de opciones de un móvil? Por otro lado, tanto los símbolos como la misma discapacidad no existen en el vacío, sino que se constituyen en relación con la cultura en que se inscriben, con sus interpretaciones en torno al fenómeno, sus valores acerca de lo que es normal, la apertura a la diversidad, etc. Por todo ello merece atención el uso que hacemos al señalizar la accesibilidad.

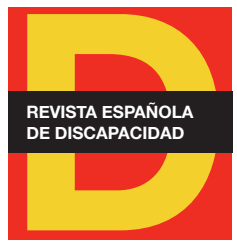

Para citar:

Bascones, L. (2018): "Lo que cuenta el (nuevo) Símbolo Internacional de Accesibilidad". Revista Española de Discapacidad, 6 (II): 205-212.

Doi: <https://doi.org/10.5569/23405104.06.02.11> 


\section{La semántica: de la discapacidad a la accesibilidad y lo humano universal}

El logo de décadas anteriores, a pesar de representar una persona en silla de ruedas, lo que pudiera restringir su aplicación a la accesibilidad en el medio físico, ha alcanzado una popularidad muy amplia a escala internacional y se ha aplicado a diferentes entornos: hasta para significar la accesibilidad de la web por parte de Google. ¿Por qué cambiar este icono? EI SIA clásico ha sido objeto de diversas críticas (Ben-Moshe y Powell, 2007; Jones, 2013):

- Su trazo estático presenta la discapacidad desde rasgos pasivos.

- La silla de ruedas, el producto de apoyo, ocupa el centro del logo. De hecho, las primeras propuestas de este símbolo se reducían a la silla de ruedas, a la que se añadió una cabeza por motivos estéticos. Anteponer la prótesis puede contribuir a la despersonalización y cosificación, y de esta manera al estigma o prejuicio negativo.

- Representar/visibilizar únicamente un colectivo específico (usuarios de silla de ruedas) y, en consecuencia, referir la accesibilidad física, frente a la heterogeneidad de perfiles y requerimientos del ámbito de la discapacidad (visual, auditiva, etc.).

- Afianzar la dicotomía entre la persona con discapacidad (minoría), representada en el logo, y una mayoría ausente del mismo: los 'normales'/capacitados. En este sentido, contribuir a la segregación.

Figura 1. Imágenes del antiguo y nuevo Símbolo Internacional de Accesibilidad

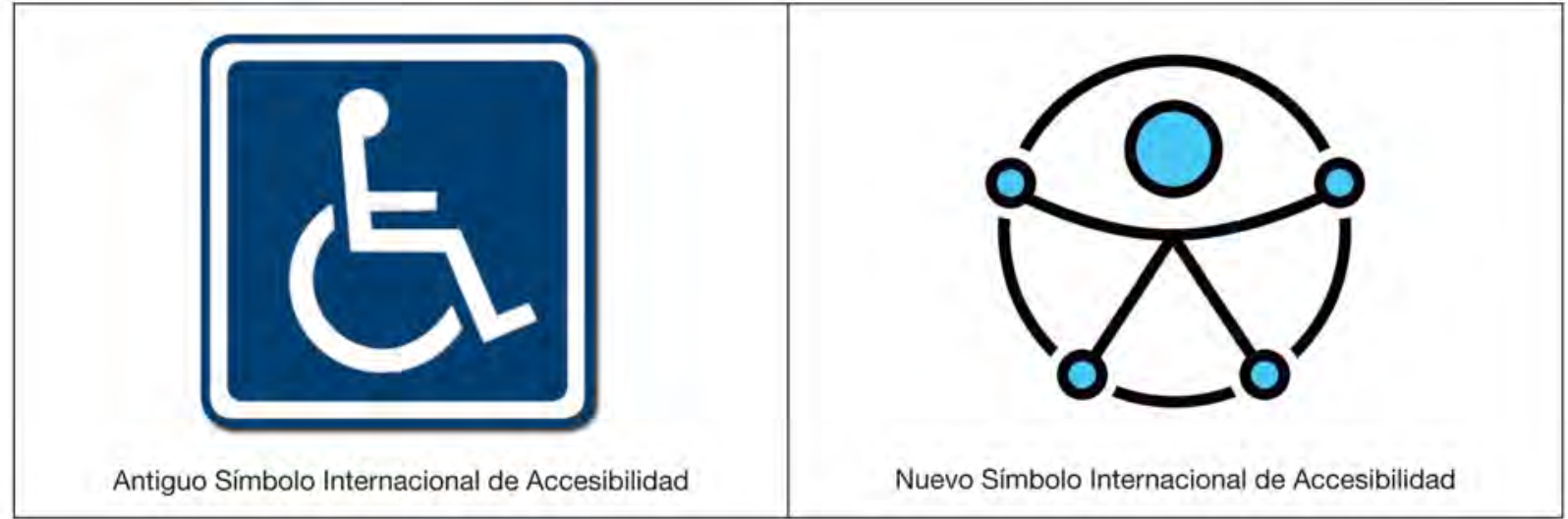

Fuente: Wikipedia y http://www.un.org/fr/webaccessibility/logo.shtml.

El nuevo logo pretende invertir los términos, al representar "una figura humana universal". Tal como describe Naciones Unidas (2015): 
Bajo la concepción de generar un símbolo distintivo y sin estigmatizaciones, la Unidad de Diseño Gráfico del Departamento de Información Pública de la ONU en Nueva York creó este nuevo logo para su utilización mundial al cual se denominó "Símbolo de Accesibilidad".

El alcance global de este logotipo se transporta por un círculo, con la figura simétrica orientada a representar una armonía entre los seres humanos en la sociedad. Esta figura humana universal con los brazos abiertos simboliza la inclusión para las personas de todos los niveles, en todas partes.

El logotipo de Accesibilidad fue creado para su uso en productos de información pública impresos y electrónicos para crear conciencia acerca de los problemas relacionados con la discapacidad, y se puede utilizar para simbolizar productos, lugares y todo lo que es "para personas con discapacidad" o "accesible".

La imagen clásica ponía el foco en lo concreto: la silla. El relato sobre la accesibilidad universal era un añadido discursivo. En el nuevo logo, una persona en pie con los brazos abiertos rodeada por un círculo, ya no se encuentran marcadores que evoquen discapacidad, pone el acento en lo universal a costa de ser más abstracto que el anterior.

La relación entre un significante (la forma de logotipo) y un significado (la accesibilidad) es, en todos los casos, convencional, responde a un código que o se comparte ya -y entonces funciona como ausente, es parte de la memoria del receptor- o se ha de aprender (Giroud, 1986: 56). Sin embargo, la convención puede ser implícita o explícita, más o menos motivada. En el SIA clásico la silla de ruedas sugiere una evocación inmediata y concreta: se basa en un código motivado y relativamente explícito, aunque siempre requiere interpretación. El nuevo logo de accesibilidad, más abstracto, requiere un proceso de aprendizaje y asentamiento cultural. En un caso similar, no hay nada que permita asociar de forma directa los aros al movimiento olímpico, un símbolo hoy conocido mundialmente. Fue necesario un proceso de aprendizaje de años y de repetición en el uso para conseguirlo. Para que un símbolo sea eficaz ha de pasar un test importante: su popularización. ¿Lo pasará el nuevo SIA? ¿Hay bases para ello?

Según afirma Naciones Unidas, el nuevo logo de accesibilidad "fue revisado y seleccionado por los Grupos Focales sobre Accesibilidad", se basa en la participación y validación de organizaciones de la sociedad civil, incluidas entidades de personas con discapacidad. Requiere, sin duda, de un proceso de aprendizaje, que puede ser en especial arduo para personas con dificultades cognitivas. Como ventaja, cabe apuntar dos antecedentes que pueden contribuir a la popularización del icono:

- Desde hace años el Sistema Operativo Apple representa la accesibilidad a través de una persona en pie con los brazos abiertos en un círculo, como después ha hecho también Android. ¿Nos suena?

- Desde un aliento cultural más largo, es difícil no advertir la afinidad entre el nuevo logo y el célebre hombre de Vitrubio, el dibujo de Leonardo da Vinci que representa la medida del hombre en relación con el cosmos. Este hombre en pie con los brazos abiertos enmarcado en un círculo es una de las imágenes más conocidas del arte renacentista e impresa en nuestra cultura en camisetas, tazas, etc. 
Figura 2. Imágenes del símbolo de accesibilidad Apple y el hombre de Vitrubio

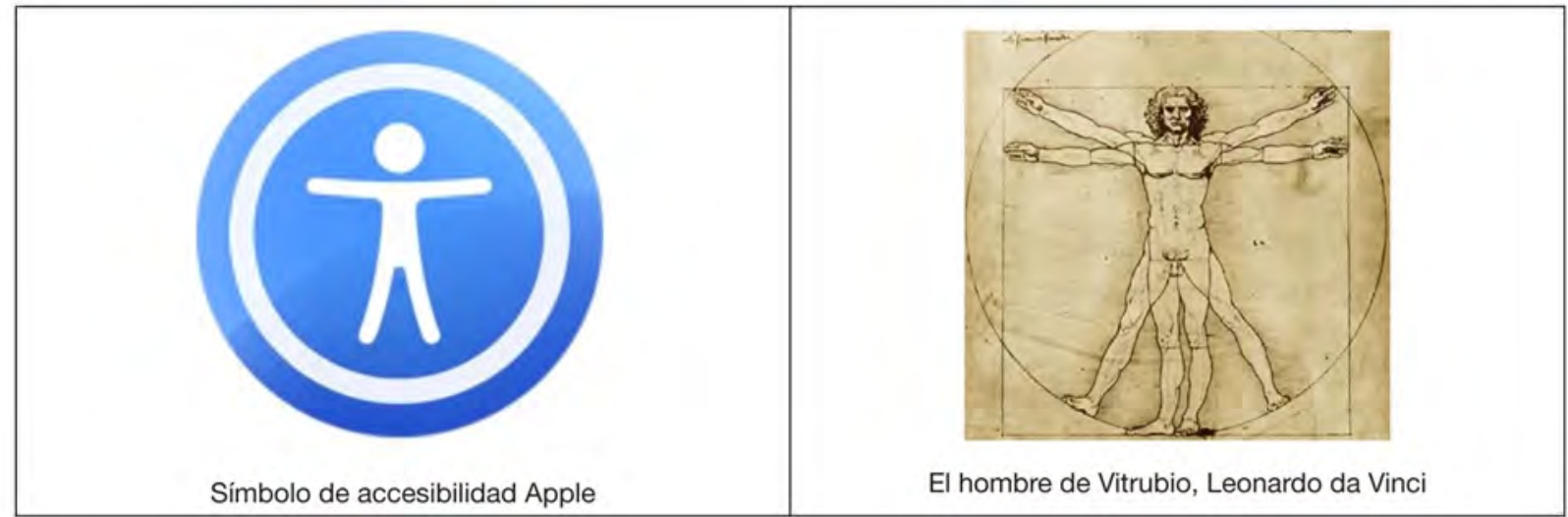

Fuente: https://communities.apple.com/es/community/accessibility y https://es.wikipedia.org/wiki/Hombre_de_Vitruvio.

Una vez considerados aspectos de diseño y funcionamiento semiótico-cognitivo de los logos, nos adentramos en su uso.

\section{Pragmática: lo singular, lo universal y las aplicaciones privativas}

Junto al logo de la silla se han multiplicado iconos singulares de accesibilidad, y una tensión entre los usos privativos y generales del símbolo.

\section{- La profusión de las singularidades}

La ventaja de lo concreto del logo clásico, la silla de ruedas, ha sido simultáneamente su límite para expresar realidades diferentes. En años recientes se han multiplicado iconos singulares y distintivos característicos de distintos colectivos, a partir precisamente de los productos de apoyo que los caracterizan: un bastón para indicar accesible a personas ciegas; un audífono con una barra cruzada, para indicar la existencia de bucle magnético... de hecho, se da cierta controversia en relación con la imagen para representar la accesibilidad cognitiva, más difícil de designar a falta de un anclaje concreto. Además, en distintos espacios (autobuses, plazas de aparcamiento) se disponen logotipos de personas mayores (el bastón) o mujeres embarazadas. 


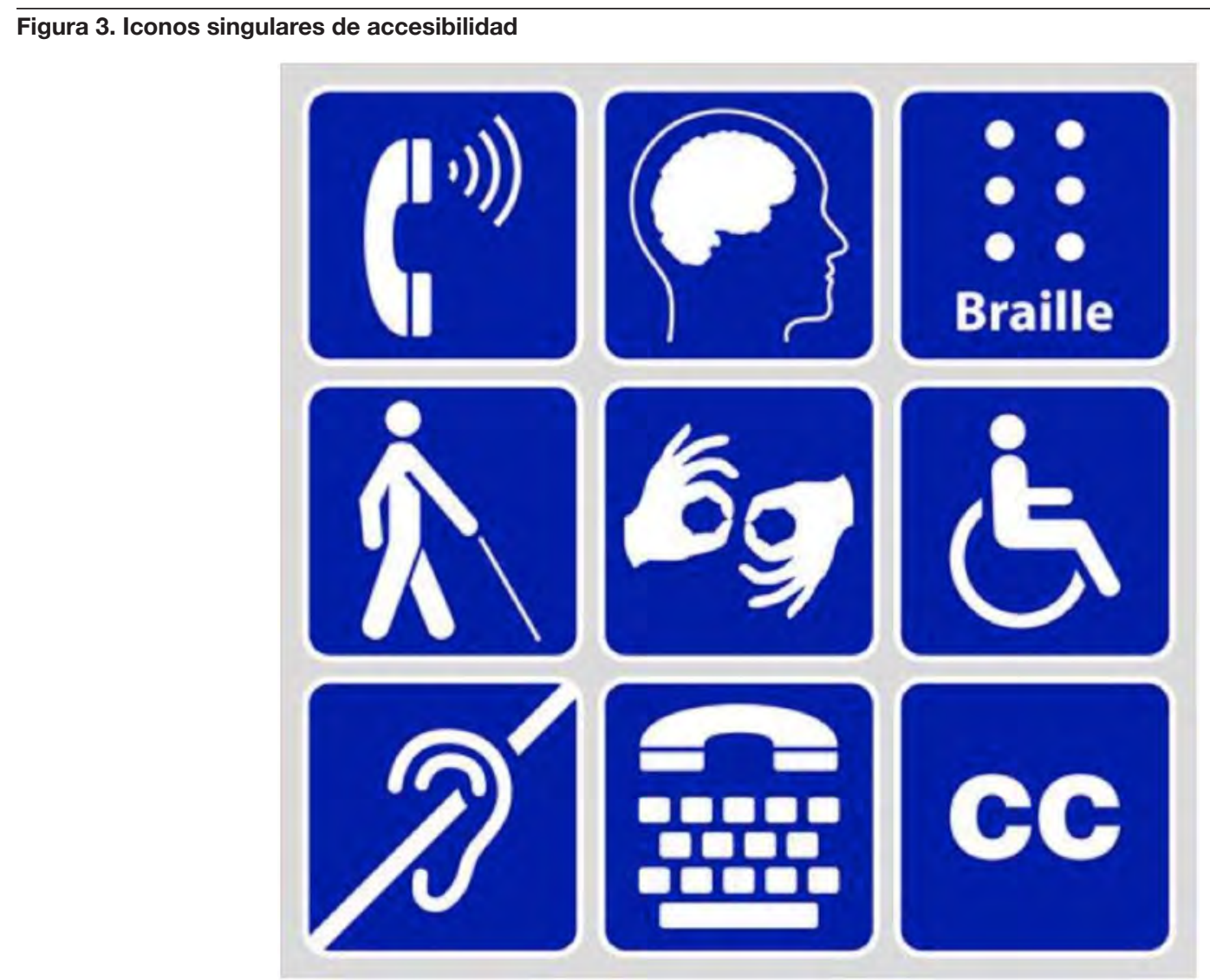

Fuente: https://www.123rf.com/stock-photo/accessibility_icons.html?imgtype=0\&sti=mz0v2wr0f4vf0v5pz2|.

Estas representaciones señalan usos y recursos del espacio, como el bucle magnético en una instalación o las diferentes entradas previstas en un autobús (entrada delantera: personas con bastón, dificultades de movilidad; entrada central, con la rampa: silla de ruedas). También, de paso, visibilizan colectivos diferenciados, con un sentido de afirmación pública de identidades específicas que quedaban difuminadas en la silla de ruedas. Cabe prever que por ello van a convivir con el nuevo SIA, tal como lo hacen ahora.

\section{- Entre lo universal y el uso privativo}

La tensión entre lo 'universal' y lo 'privativo' o reservado a un colectivo del icono de accesibilidad parte de la misma precisión de su uso previsto: “... se puede utilizar para simbolizar productos, lugares y todo lo que es 'para personas con discapacidad' o 'accesible'” (Naciones Unidas, 2015). Es habitual encontrar en titulares periodísticos la expresión "Accesibilidad Universal para las personas con discapacidad”.

De modo paradójico, la pretensión de significar lo universal se combina, en la práctica, con la demarcación de límites en el espacio, como las plazas de aparcamiento reservado o los baños adaptados, cuyo sentido es la reserva (preferencia, pertenencia) al grupo minoritario. Al demarcar el espacio afianza también el límite 
entre un nosotros (el estándar dominante) y los otros, la minoría externa al estándar. De hecho, para el uso autorizado de las plazas de aparcamiento reservado es preciso contar con una tarjeta que reconoce oficialmente la condición de movilidad reducida. Incluso marca en el tren un vagón destinado a los "desheredados de la tierra" que usen bastones, sillas, necesiten bucle magnético... (Maraña, J. J., 2016). No puedes ir al otro vagón.

Mediante esta división del espacio, el SIA se puede convertir en un significante de segregación, al marcar los espacios 'accesibles' (para discapacitados) respecto a aquellos para público general (Jones, 2013). En consecuencia, cargarse de estigma, de connotaciones negativas, tanto el mismo símbolo como aquellos espacios separados, y a quienes están destinados a hacer uso de ellos, en un bucle que se retroalimenta. Por este camino, lo 'accesible' vuelve a ser y será un asunto de minorías, un parche velado por una niebla de evocaciones de separación, marginalidad, tragedia. Y la afirmación, en contrapunto, de la normalidad. Y sin embargo, hoy día sigue siendo preciso combinar y compaginar el diseño universal e inclusivo con medidas de igualdad de oportunidades como las plazas reservadas o incluso el señalamiento de espacios con una atención al cliente/ciudadano distinta a la habitual. Ahora bien, siempre que sea posible, estos lugares y servicios han de distribuirse en espacios fluidos y con la mayor apertura posible. Por ejemplo, que todo el tren sea accesible, con espacios flexibles, modulares, que permitan el uso por distintos públicos, también aquellos con movilidad reducida u otros requerimientos. Espacios, productos y servicios multifuncionales, abiertos a la diversidad humana: funcional, de edades, género, tamaño, situaciones, cultura. Las TIC presentan en este sentido quizá mayor versatilidad que el espacio físico. Estudiemos cada caso para exprimir su potencial inclusivo.

\section{Incluir desde la diversidad: el camino de cuadrar el círculo}

Cada signo comporta valores ideológicos y efectos prácticos. Tiene un sentido de presentación pública y reflexiva, de cómo nos comprendemos las personas con discapacidad/diversidad funcional. El problema del nuevo Símbolo Internacional de Accesibilidad no será el aprendizaje, el test de la popularización: hay antecedentes culturales arraigados y propone connotaciones positivas. Puede costar al principio, y se puede acompañar de 'anclajes textuales', orientaciones para su mejor comprensión, tal como los autobuses de piso bajo al comienzo de los 90 llevaban la leyenda en el lateral 'pensado para todos'.

El nuevo símbolo promueve una apertura de la mirada, del imaginario de lo accesible para situarlo en la diana de lo humano universal, en toda su complejidad. En contrapartida persiste, tanto por la definición como por los usos divisorios del espacio, la adscripción de la accesibilidad a una minoría 'maldita'. Es preciso combinar las medidas de acción positiva hacia una colectividad discriminada en el acceso y la participación, como la reserva de plazas, con entornos lo más fluidos posible.

Como dicen Ben-Moshe y Powell (2007: 394), "si se aplicaran los principios de diseño universal de manera plena, no necesitaríamos el SIA, puesto que todos los espacios y objetos se habrían diseñado desde el principio para una población diversa". La cuadratura del círculo, la inclusión desde la diversidad, no se 
pueden resolver matemáticamente, por decreto. Ya lo vio da Vinci y su dibujo pretendía dar respuesta simbólica a esta paradoja. Que gane terreno el reconocimiento de la diversidad y el valor de lo universal desde usos específicos o se mantenga la divisoria y los usos segregados, estigmatizadores de objetos, espacios y personas depende de nuestras prácticas conscientes al diseñar entornos, señalizarlos y hacer uso de ellos. 


\section{Referencias bibliográficas}

Ben-Moshe, L. y Powell, J. W. (2007): "Sign of our times? Revis(it)ing the International Symbol of Access". Disability \& Society, 22 (5): 489-505 (en línea). <www.tandfonline.com/doi/pdf/10.1080/09687590701427602>, acceso 11 de diciembre de 2018.

Giroud, P. (1986): La semiología. México. Siglo XXI.

Jones, C. (2013): “"For them, not us": How ableist interpretations of the International Symbol of Access make disability". Critical Disability Discourse/Discours Critiques dans le Champ du Handicap, 5: 67-93 (en línea). <https://cdd.journals.yorku.ca/index.php/cdd/issue/view/2144>, acceso 12 de diciembre de 2018.

Naciones Unidas (2015): Un nouveau symbole d'accessibilité (en línea). <http://www.un.org/fr/webaccessibility/ logo.shtml>, acceso 12 de diciembre de 2018.

Maraña, J. J. (2016): Vagón de cola (en línea). <http://derechoshumanosya.org/vagon-de-cola/>, acceso 11 de diciembre de 2018. 